\title{
REFLECTING TOGETHER ABOUT TENURE AND PROMOTION
}

\section{A FACULTY LEARNING COMMUNITY APPROACH}

\section{Leslie G. McBride, Janelle DeCarrico Voegele, Portland State University}

What happens when faculty representing various disciplines and career stages reflect together on the tenure and promotion process? How does the learning community they form facilitate development of their academic portfolios, and what insights into various forms of scholarship does it provide? This chapter addresses these questions. It describes the learning community over a five-month period, explains how academic portfolio development was used as a common reference point for addressing tenure and promotion issues, and summarizes insights and perspectives shared among faculty members as they tried to understand the value of diverse forms of scholarship.

Boyer's (1990) landmark book, Scholarship Reconsidered, called into question the restricted approach toward scholarship taken on most college and university campuses and argued convincingly for the value of multiple forms of scholarship, including the scholarship of teaching. Although academics have found the four complementary types of scholarship in Boyer's extended model (discovery, integration, application, and teaching) both affirming and liberating, junior faculty members have hesitated to stray too far from either disciplinary norms or department expectations regarding the type of scholarly work they should produce for a successful promotion and tenure review.

At Portland State University (PSU), hesitancy on the part of new faculty is particularly apparent in regard to scholarship that focuses on servicelearning and civic engagement-what Ward (2003), in an extension of Boyer's work, refers to as the scholarship of engagement. In new faculty 
orientation sessions and during individual promotion and tenure consultations, new and untenured faculty inevitably express curiosity about the scholarship of engagement and its value compared to traditional scholarship. They are particularly interested in learning how their disciplinary colleagues regard the scholarship of engagement and about the kind of support it typically receives during promotion and tenure review (O’Meara \& Rice, 2005; Ward, 2003).

At the Center for Academic Excellence at PSU, we responded to such concerns by designing a faculty learning community with an embedded academic portfolio development component. We used participants' initial consideration of how to organize their portfolios and what to include in their written narratives as a common reference point for exploring the range of scholarly activity present within the group. This approach stimulated deeper inquiry into diverse forms of scholarship and, as a result of learning community discussions, participants gained helpful insights into the faculty review process.

PSU is an urban university that enrolled nearly twenty-eight thousand full- and part-time students in 2009. It has nearly fifteen hundred fulland part-time faculty and offers 213 degree programs. The university's motto, "Let Knowledge Serve the City," carries a great deal of meaning for both faculty, who refer to it regularly in the context of their work, and administrators, who build on it when establishing priorities, fundraising, and during promotional campaigns. Recently identified in the Chronicle of Higher Education as one of five "smaller institutions that have either honed great reputations in their markets or are on the rise" (Carlson, 2010, p. 1), PSU has been recognized for its service-learning and senior capstone programs; its learning communities, internships, and cooperative learning; and, related to these, its outstanding community involvement. In 1996, PSU institutionalized support for the scholarship of community engagement by including appropriate explanations and examples in a revision of university promotion and tenure guidelines. More recently, a year-long process involving key administrators produced a 2007-2009 vision statement describing PSU's leadership in engagement.

The academic portfolio learning community project emerged out of this campus context. As director and assistant director for the university's faculty development programs, we wanted to support faculty members' attempts to understand and respond to institutional expectations for engagement and service to the city, while at the same time attending to disciplinary norms and expectations for scholarship within academic units. Building on previous work that explored shifting institutional 
norms pertaining to definitions of scholarship on our campus (Rueter $\&$ Bauer, 2005), we wanted to better understand how faculty interpreted these expectations.

Although the process-driven learning community framework we decided on was time intensive and at times unwieldy, we chose it because of the relatively untapped potential of faculty learning communities for rendering the tenure review process more transparent (Cox, 2004). We also wanted to explore how development of academic portfolios (Seldin $\&$ Miller, 2009) and investigation of scholarship of teaching, learning, and engagement literature within a learning community framework would contribute to members' understanding of the promotion and tenure process. We assumed that an implicit understanding of this process would emerge when learning community discussions were coupled with the work that faculty did on their individual academic portfolios between meetings. We also assumed that this understanding could be made more explicit through group reflection activities that focused attention on participants' developing understanding of promotion and tenure.

\section{The AIM Model}

For sixteen years, faculty and staff working in the Center for Academic Excellence have used a learning community approach to encourage innovative teaching and scholarly activity. This approach, currently referred to as the Academic Innovations Mini-Grant (AIM) program, has focused primarily on the scholarship of teaching and learning and the scholarship of engagement. However, the same approach has also been used to encourage faculty to participate in projects they might not be able to pursue without staff and resource support. Incorporating community-based learning into established courses, transitioning from traditional classroom to blended or fully online course formats, and developing innovations in program assessment are three examples of faculty innovation and curricular change supported by AIM groups.

Currently AIM provides the organizational support for three to five faculty learning communities each year. These groups typically involve ten to fifteen members who meet together once a month for five to six months, although the overall time frame and frequency of meetings reflect each group's basic goals. Facilitation duties are often shared between a faculty developer and a member of the group. Participating faculty receive stipends ranging from five hundred to fifteen hundred dollars for regular participation and development of a work product that is described in general terms in the call for proposals. Past work products 
have included curricular and course redesign in such areas as community engagement, sustainability, and blended learning; scholarship of teaching (or engagement) manuscript drafts; and written reflections in Our Voices, an annual publication on teaching and learning at PSU produced by the center. Although we encourage faculty participation in AIM learning communities by offering stipends, we also listen carefully to the felt needs that faculty express and attempt to integrate our understanding of these into AIM program themes. When appropriate, we align AIM themes with institutional priorities and strategic initiatives. Often these overlap. For example, campus priorities related to engaged scholarship, coupled with faculty curiosity regarding levels of support this scholarship received across departments, proved to be important incentives for participation in the AIM academic portfolio group.

Within the normal range of topics or goals that AIM groups pursue, those of the academic portfolio groups were somewhat different. These groups offered participants the opportunity to focus for a brief time on themselves-their career goals, their faculty responsibilities, and their research and scholarship-and share insights and resulting work in a learning community framework. We describe how the two groups were organized, their schedule, and details of specific activities in the next section.

\section{AIM Academic Portfolio Groups}

The call for AIM academic portfolio proposals was distributed during fall 2008 and again in fall 2009. Ten faculty members applied and were accepted each year. The sixteen tenure-track, two tenured, and two fixedterm faculty represented professional schools (business, education, engineering, social work, and urban and public affairs); liberal arts; fine and performing arts; honors; and general education. A member of the library faculty also participated. Of the twenty participants, three were men. Some participants were in their first year at PSU; others were anticipating promotion and tenure review during the following academic year. One participant, returning to the faculty after serving a five-year term as associate dean, was pursuing promotion to full professor. In response to the first call for proposals, a tenured full professor and an untenured assistant professor in the same professional school applied as a team, proposing to develop a teaching portfolio (the junior member) and a literature review on the use of student evaluations in promotion and tenure decisions (the senior member). Their goal was to better understand the relative merits and contributions of each approach to the tenure and 
promotion process and to share what they learned in presentations to their colleagues.

Both groups met monthly from January through May and followed the same general schedule. We assumed more active leadership roles than usual within a faculty learning community format because most members were junior faculty who had many questions about the promotion and tenure process and were experiencing varying degrees of stress related to it. Our first priority was to establish an environment in which participants felt comfortable asking questions about various aspects of the promotion and tenure process and sharing early drafts of their portfolio narratives. To encourage this, we provided ample time during the first meeting for participants to get acquainted. We also created a composite list of the group's reasons for participating, the benefits they expected to gain, and the collective goals members held for creating portfolio drafts. We distributed this list during the first session as a means of initiating discussion about the learning community process and what results participants might expect. Early on we also wanted to familiarize members with different portfolio types and introduce them to related literature. We asked them to read chapters from Scholarship Reconsidered (Boyer, 1990), selections from O'Meara and Rice's (2005) work tracing the history of efforts to redefine scholarship, and further elaborations on the scholarship of teaching (Hutchings \& Shulman, 1999) and the scholarship of engagement (Ward, 2003). We encouraged learning community members to deepen their understanding of the types of scholarship described in these readings through general discussion and sharing accounts of disciplinary experiences.

The second session included a key activity, Will It Count?, designed to stimulate extended discussion about what made work scholarly and what constituted scholarship. Participants read descriptions of academic work in teaching, research, and service (both community and professional), discussed in small groups how colleagues in their respective units would value each example, and then discussed results with the entire group. Among the examples that participants considered were these:

- Published an article in a discipline-based refereed journal

- Published an article on student learning and technology in a refereed journal

- Published an article on assessment of community-based learning outcomes in the refereed journal Community Partnerships

- Published an article in a nonrefereed online journal 
- Researched, drafted, and worked to pass legislation related to a scholarly agenda

- Wrote and received a grant examining the civic purposes and responsibilities of courses at a university

- Made regular contributions to a research-oriented blog

- Completed a comparative assessment of face-to-face and online learning

- Presented teaching, learning, and community-based research strategies at a national conference

Lively conversation ensued as participants shared their perspectives on work from each category and explained their opinions. As the discussion progressed, participants identified characteristics that strengthened the best examples and specified how weaker examples might be improved. Finally, the group considered how they could apply what they learned from Will It Count? to their own work. During this session, we also introduced basic portfolio types, making special reference to Seldin and Miller's (2009) book describing the academic portfolio. The wide variety of examples presented in the book stimulated participants' thinking about their own portfolios and provided background context needed to begin designing their own narrative statements.

Sessions 3 and 4 marked a shift in focus from general background information to the progress participants were making on their portfolio outlines and narrative themes. Participants shared basic organizational plans for their portfolios during the third session and described themes they were considering for inclusion in their narratives. In groups of three, they reported on their progress and responded to three basic questions: (1) What questions or approaches do you share in common with others in your group? (2) Based on your discussion, what is unique about your portfolio? and (3) What questions do you have about your portfolio work as a result of your discussion today? The summary discussion of this process indicated that members of the learning community were beginning to think seriously about the portfolio development process and that doing so was stimulating deeper insights into various aspects of their work.

Participants brought written drafts of their narratives to the fourth session. Once again, they divided into groups of three and spent their time reading and commenting on each other's drafts. Summary discussions at the close of session 4 indicated that participants found this process helpful. Listening to issues framed from different disciplinary perspectives and responding to questions posed by colleagues in other 
disciplines shed new light and fresh perspective on familiar academic themes. Participants' awareness of the range of meanings related to different forms of scholarship increased (Albers, 2007); over time, they reported sharing their new insights with colleagues in their home departments.

The fifth and final meeting of each academic portfolio learning community was an open forum to share with nonparticipating faculty what participants had learned. We included this forum as part of the overall framework to encourage each group's reflection over the entire process. Each year's learning community planned its forum to encourage discussion and consideration of the tenure and promotion process, the merits of academic portfolio development, and different forms of scholarship. As one of two final products for which participants were responsible, the forum also ensured their accountability to the AIM program as participants reflected together over what they had learned, set priorities as they developed forum goals, and considered the best design to achieve them. An average of thirty people attended each forum, including faculty, department chairs, deans and associate deans, and vice provosts. Those completing evaluation forms distributed at the conclusion of the 2009 forum indicated they found the information useful or very useful, and rated the overall presentation quality as outstanding. They wrote that as a result of attending the forum, they were more aware of variations in the promotion and tenure process across programs and of the range of definitions of scholarship used within them. A few commented that the forum renewed their interest in Boyer's (1990) vision for multiple forms of scholarship.

The only remaining responsibility for learning community participants at this point was completion of their academic portfolio outlines and the accompanying narrative statements for one section. Members of both groups struggled to fulfill this requirement. Some were overloaded by teaching and related student responsibilities that coincide with the end of an academic year. Others had simply procrastinated too long. At this point, the stipend of five hundred dollars played a key role, providing the additional motivation needed to persevere and complete the second work product.

\section{Outcomes}

Because of confidentiality concerns around tenure and promotion review, some outcomes from the AIM portfolio groups may never be known. Short-term outcomes, both expected and unexpected, related to 
portfolio development and increased understanding of the promotion and tenure process.

The expectation that each faculty member would develop an academic portfolio outline, including an expanded narrative for one section, provided some members added clarity and insight into their work. One member observed that in the press of daily responsibilities, she had lost sight of the larger pattern of her work. Working on her portfolio brought her back in touch with this pattern and helped her recognize the significance of work she had either forgotten or not recognized previously.

We also expected that the learning community process would render promotion and tenure review more transparent to members. Portfolio development, group discussion, readings, and group activities like Will It Count? did just that. Faculty described themselves as more confident of their ability to prepare a portfolio that would represent their work accurately, and they felt better prepared for the review process. Checking in with us early in the academic year following her AIM participation, one faculty member observed how much more confident she felt as she assembled her portfolio and entered the initial phase of her promotion and tenure review. When we asked her to elaborate, she used as an example her consideration of the peers she recommended as external reviewers. Because of participating in the AIM group, she was much more intentional about whom she recommended, considering their areas of expertise, the type of institution where they worked, and the nature of their responsibilities. She observed, "I never would have considered these factors, but after participating in the group, I realize they may make a difference in how my work is regarded."

We hoped that the conversations about promotion, tenure, and what constitutes scholarship that took place in the learning community would encourage group members to engage in extended conversations beyond the group. Previous research conducted on our campus revealed numerous indicators of progress toward understanding and acceptance of expanded forms of scholarship; however, agreement on the value of new forms of scholarly products continued to vary widely across campus (Rueter $\&$ Bauer, 2005). Several AIM members became leaders or mentors in their units, often facilitating conversations that furthered departmental understandings of the potential value of innovative academic products and processes. The participating library faculty member facilitated a department retreat on representation of diverse forms of scholarship. A faculty member in urban planning with experience engaging students in communitybased projects met with her department chair to compare their interpretations of the scholarship of engagement and clarify implications 
related to tenure and promotion. In the process of updating her portfolio, a senior faculty member gained insight into her practice of designing and teaching innovative courses (one was Creativity in Business) and using innovative approaches to learning in the classroom. Realizing that her natural ability to innovate and her experience in curricular and course design made her a useful resource, she now shares her expertise in these areas with other faculty. Finally, the department chair and assistant professor who teamed up to focus on the relative use of teaching portfolios and student evaluations in the promotion and tenure process shared results of their inquiry with disciplinary colleagues, encouraging them to enlarge the review process to include scholarship of teaching indicators.

\section{Insights and Lessons}

We will no doubt experience more insights and learn more lessons as we continue to sponsor academic portfolio groups. Three lessons became clear to us so early in our work that we believe they are important to overall success.

\section{Mutual Trust Is Essential to Establishing Effective Peer Support}

The sense of trust that participants experience in the group facilitates honest, straightforward sharing of personal opinions and experiences related to various stages of academic review. Initially participants needed ample opportunity to explore common ground. Providing a written composite of members' goals and expectations for their learning community was one way of supporting this process. Participants discussed their scholarly agendas and their understanding of expectations held by their units, their deans, and the university. They were intensely interested in sharing stories of their personal experiences and checking their understanding of various policies and procedures with one another. Trust developed along the way, nurtured by adequate time to support these early conversations.

\section{Support the Process and Outcomes of Deep Reflection}

One of the strengths and outcomes of portfolio development is the deeper-than-usual reflection about teaching, scholarship, and service that it encourages. As participants reflected on work products in relation to their professional goals and their units' promotion and tenure guidelines, questions surfaced that reflected multiple levels and nuances of the process. 
Different perspectives on "what counts" created lively discussions; comparison of personal records of accomplishment to written descriptions of responsibilities and disciplinary norms prompted soul searching; and, later, portfolio presentation and peer feedback sessions deepened members' understanding of how to frame the insights and creative solutions gained through their collective inquiry process. As facilitators, we searched out information to address questions arising from this multilevel reflection and review. We also developed focused questions to help guide peer feedback sessions as portfolios were developed; these played a helpful role in preventing discussions over individual portfolios from becoming too wide ranging.

\section{Public Forum Is Key to Diffusion of Information}

The public forum that constituted participants' fifth and final session was a key element in this program. Although participants were resistant to the idea initially, as they gained confidence from their own portfolio development, group discussion of various forms of scholarship, and a more extensive understanding of tenure and promotion practices, they gradually agreed that that there were good reasons to share what they had learned in a formal presentation. Planning for and holding the forum required further reflection and synthesis of knowledge gained as members decided what was important to cover and how to organize the forum for its greatest effect.

\section{Conclusion}

Cox (2004) and others have noted higher education's failure to authentically and effectively respond to requests from new faculty for a more comprehensible tenure system. Our initial efforts to combine a faculty learning community framework with academic portfolio development demonstrate a potentially effective way to address the alignment between institutional priorities and faculty reward structures.

During a particularly poignant moment when the group was deeply engaged in discussion, a participant described a senior faculty member's response to her question regarding how she might judge whether she had enough publications to her credit: "I was told, "Ask the faculty member who recently has had a successful review how many publications he or she had and then just add one more."' Participants grew quiet as they considered her comment; then, one by one, they began to chuckle as the absurdity of the end result gradually dawned. After the entire group had enjoyed a good laugh, it claimed as its slogan, "Just add one more!" and 
determined that it could come to a shared understanding of promotion and tenure requirements that would serve it much better. At that point, participants began giving serious consideration to what really counts in scholarship, teaching, and service.

Through the learning community format, review and discussion of literature describing scholarship in its different forms, and a clearer understanding of portfolio use and development, participating faculty have acquired the ability to recognize and help promote diverse forms of scholarship. Indeed, the learning community became much more than a group helping one another assemble an academic portfolio. Rather, the portfolio and learning community framework provided a departure point for a deeper, more significant faculty conversation about the promotion and tenure process, what counts toward advancement, and why.

\section{REFERENCES}

Albers, C. (2007). Developing a shared meaning of scholarship to enable the revision of a promotion policy. International Journal for the Scholarship of Teaching and Learning, 1(1). Retrieved from http://academics .georgiasouthern.edu/ijsotl/current.htm

Boyer, E. L. (1990). Scholarship reconsidered: Priorities of the professoriate. San Francisco, CA: Jossey-Bass.

Carlson, S. (2010, November 19). How to build a perception of greatness. Chronicle of Higher Education, pp. A1, A11-A13.

Cox, M. D. (2004). Introduction to faculty learning communities. New directions for teaching and learning: No. 97. Building faculty learning communities (pp. 5-23). San Francisco, CA: Jossey-Bass.

Hutchings, P., \& Shulman, L. S. (1999, September/October). The scholarship of teaching: New elaborations, new developments. Change, 31(5), 10-15.

O'Meara, K., \& Rice, R. E. (Eds.). (2005). Faculty priorities reconsidered: Rewarding multiple forms of scholarship. San Francisco, CA: Jossey-Bass.

Rueter, J., \& Bauer, T. (2005). Identifying and managing university assets: A campus study of Portland State University. In K. O'Meara \& R. E. Rice (Eds.), Faculty priorities reconsidered: Rewarding multiple forms of scholarship (pp. 187-208). San Francisco, CA: Jossey-Bass.

Seldin, P., \& Miller, J. E. (2009). The academic portfolio: A practical guide to documenting teaching, research, and service. San Francisco, CA: Jossey-Bass.

Ward, K. (2003). Faculty service roles and the scholarship of engagement. San Francisco, CA: Jossey-Bass. 